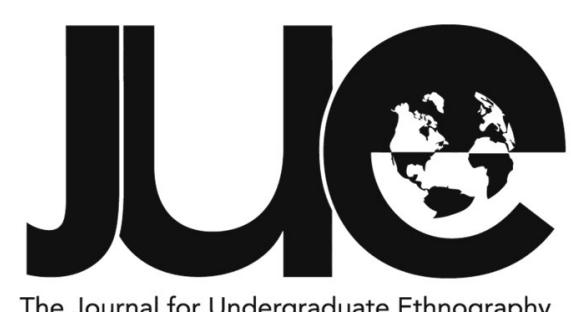

The Journal for Undergraduate Ethnography

\title{
Living with Food Allergies: The Recalibratory Body
}

\section{Megan Greenhalgh}

\section{Durham University, megangreenhalgh26@gmail.com}

\section{ABSTRACT}

As a growing global public health concern, an increasing proportion of the UK's population must live with and manage the chronic disease of food allergies. Through a multi-method approach of autoethnography, cognitive mapping, and interviewing, this research investigates what matters to the bodily experience of people living with food allergies. I work with the concepts of embodiment and affect to delineate a theorisation of the allergic body as recalibratory and argue that the adrenaline auto-injector (AAI) - the lifesaving medication prescribed to individuals with severe food allergies-is integral to the allergic recalibratory body. I demonstrate the multiple, dynamic ways in which those living with food allergies "affectively relate" to the AAl and what contributes to this. An account of the body as recalibratory is advanced to account for the dynamicism of the body's affective relations. The recalibratory body becomes a valuable tool for understanding the ways that macro-issues of AAl production shortages and the tragic occurrence of allergy fatalities as well as micro-level everyday experiences matter to those living with food allergies. The essay concludes by exploring how the concept of recalibration can expand beyond allergic bodies to understand what the body-any body-can be, do, and mean.

Keywords: embodiment; affect; body; chronic disease; food allergy 
T he rising global prevalence of food allergies presents a growing public health issue (Loh and Tang 2018). In the UK, an estimated two million people are affected by this chronic disease (Wearne 2017), a figure that is rising by five percent every year as more and more children are diagnosed (NARF 2019). Those living with food allergies must manage their condition throughout their daily lives by avoiding exposure to the allergens (specific foods) that would cause the body to react (AAFA 2015; NHS 2019b).

This research investigates the bodily experience of living with food allergies, questioning how the body becomes important to the everyday experience of managing food allergies. I work towards a delineation of the "allergic body," previously un-theorised within the social sciences, to demonstrate what matters to the everyday experience of those living with food allergies. I argue that adrenaline auto-injectors (AAIs) are integral to the maintenance and everyday life of the allergic body. In the UK, AAls are prescribed to those with severe food allergies to be administered in the event of an allergic reaction (NHS 2019b). Individuals are advised to carry their AAl with them at all times (NHS 2019a), which becomes a biomedically normative practice through which they are expected to manage their chronic disease.

As my research progressed, it became clear that how individuals related to the AAI varied. Two findings emerged: (1) there are multiple ways in which individuals with food allergies relate to the AAl, and (2) how individuals relate to $A A I$ is not fixed; rather, they shift dynamically as bodies pass through and encounter different spaces and circumstances. These shifting relations between the allergic body and the AAI are termed dynamic bodily relations to reflect the way they change. I therefore propose the concept of "the recalibratory body" in order to account for the way that the body re-calibrates in response to its dynamic bodily relations.

In this research, an understanding of the body as recalibratory becomes valuable to account for how the allergic body affects and is affected at the micro- and macro-level. Microlevel factors include the everyday experiences of individuals and their immediate social and material relations. Macro-level issues describe those that occur in the public eye and affect allergic bodies both materially and affectively. These include allergic fatalities and AAI shortages. For example, fifteen-year-old Natasha Ednan-Lapernouse died tragically on July 17th, 2016 after suffering an allergic reaction to the sesame contained in a baguette from Pret-a-Manger (Anaphylaxis Campaign 2018), prompting key changes in UK food allergen labelling regulations (FSA 2019). The recalibratory body becomes valuable for understanding how hearing of the circumstances around allergy fatalities can matter to individuals' everyday allergic experiences. Second, issues surrounding the supply of AAls have arose in recent years, making it difficult for those with allergies to obtain this life-saving medication (Kent 2020). A prescription validation process was implemented in the UK in 2018, which limited individuals to two AAls per prescription (Kent 2020). Rather than critiquing the production issues of the bioindustry, this research reflects upon the implications of such policy changes upon people's allergic experience (following Mol 2002) through a theorisaton of the body as recalibratory.

Whilst born from and concerned with the specificity of the allergic body in this research, an understanding of the body as recalibratory has further value to account for what the body, any body, can be, do, or mean. This research provides an important theoretical contribution to the long-standing history of geographical scholarship on the body. It draws upon and works with the concepts of embodiment and affect to develop a theorisation of the body as recalibratory, which foregrounds the dynamicism of the body's relations. 


\section{Approach to Research}

As someone living with a peanut allergy, which was diagnosed at a young age, my own experiences have informed this research. Two personal assumptions informed my research questions: (1) individuals with food allergies experience a heightened awareness of their body and surroundings, and (2) the EpiPen (a brand name for the generic AAI) in particular comes to matter to allergic experience. I conducted autoethnography, interviewing, and cognitive mapping to investigate:

1. What does a study of the experience of those with food allergies tell us about the body?

2. In what ways do the body's relations come to matter to the everyday experience of those living with food allergies?

3. How does the AAl come to matter to the everyday experience of those living with food allergies?

This multi-method approach enabled me to investigate both my own and others' allergic experience. My position as an "insider" to the allergic community facilitated both access to participants for this research through my social network and the building of rapport with interviewees. Rather than view my allergic identity as a potential obstacle to research, it is leveraged as a methodological tool for understanding allergic experiences (Longhurst, Ho, and Johnston 2008).

Autoethnography enabled both the scrutiny of my own embodied experience and normative assumptions about allergy management throughout the research process (Butz 2010) and a rigorous account of the implications of my positionality as an "insider" to the allergic community (Butz and Besio 2009). I sustained this immersive method over a period of five months, writing diary entries on the occasions that my allergy came up. Whilst intended as a complementary method, autoethnography proved instrumental to the theorisaton of the recalibratory body. It provided intimate insight into my allergic experience, allowing me to identify the instances in which the AAI came to matter as well as when the ways that I relate to the AAl alter.
I avoided the presumption that by way of my allergic identity I could attend to all allergic experiences, remaining open to the potential for others' allergic experience to differ (as Latour 2004 recommends). Semi-structured interviews and cognitive mapping allowed different normative assumptions about allergy management and the multiple ways in which allergic individuals may relate to the AAl to come to the fore. I conducted an interview with one professional in the field, Kate Latchford from the Anaphylaxis Campaign-a non-profit organisation that advocates on behalf of those living with food allergies in the UK-to ascertain the key issues it addresses regarding the everyday experiences of those living with allergies. Latchford brought to my attention that the EpiPen was a brand of adrenalin-autoinjector (AAI), exposing my assumption that individuals in the UK were prescribed an EpiPen. As a result, this article uses the generic term AAl to refer to any of the three brands on the global market: Jext, Emerade, and Epipen (Medicines and Healthcare products Regulatory Agency 2019). However, brand names feature where participants use the term.

To access a diversity of allergic experiences, I conducted seventeen semi-structured interviews with individuals of a mix of ages and genders with a variety of food allergies (table 1). I recruited fourteen participants via convenience sampling from an extended social network, and I used snowball sampling to connect with subsequent participants (Bradford and Stratford 2005). The majority of participants I interviewed were white women under 30 years of age. Given the lack of wider representation of the allergic population, I turned to the online allergic community and found a further three participants from an online support group. Although the sample was largely homogenous in terms of gender, age, and racial identities, it included a diversity of allergic experiences: individuals' stages of diagnosis varied (some had lived with the condition for many years whilst others were diagnosed very recently), some allergies were late-onset or exercise-induced, and many also had other non-related food allergies.

Alongside the interviews, I asked the nine participants whom I met face-to-face to draw a map of their awareness of their allergy. 
Table 1: Research Participant Demographics and AAI Use

\begin{tabular}{|l|l|c|c|c|c|c|}
\hline \multicolumn{2}{|l|}{} & Total & Female & Male & $<30 y r s$ & $>$ 30yrs \\
\hline \multirow{2}{*}{ Number of Participants } & 17 & $13(76 \%)$ & 4 & $12(70.6 \%)$ & 5 \\
\hline \multirow{4}{*}{ Food Allergy } & Tree Nuts & 8 & 6 & 2 & 6 & 2 \\
\cline { 2 - 7 } & Peanuts & 4 & 2 & 2 & 3 & 1 \\
\cline { 2 - 7 } & Shellfish & 2 & 1 & 1 & 1 & 1 \\
\cline { 2 - 7 } & Multiple & 3 & 3 & - & 2 & 1 \\
\hline \multirow{2}{*}{ AAl Prescribed } & Yes & 16 & 13 & 3 & 11 & 5 \\
\cline { 2 - 7 } & No & 1 & - & 1 & 1 & - \\
\hline \multirow{2}{*}{ AAl Carried } & Yes & 13 & 13 & 1 & 11 & 4 \\
\cline { 2 - 7 } & No & 2 & - & 2 & 1 & 1 \\
\hline
\end{tabular}

Cognitive mapping was useful to better understand embodied experiences within and between particular spaces (Gieseking 2013). Through the combination of drawing and talking in this method, I drew out the immersive aspects of participants' allergic embodiment (Hayes-Conroy 2010), asking, for instance, "how do you feel in that particular space?"

\section{Theorising the Allergic Experience}

As food allergies have gained prevalence, so too has academic interest. The psychosocial impact of food allergies on individuals is well recognised within sociology, anthropology, public health, and geography. Findings of a recent review of the impact of food allergies on mental health highlight the negative impact that food allergies can have on the quality of life of children, adolescents, and their families, and explains that food allergies are associated with higher risks of depression, anxiety, and PTSD/S (Feng and Kim 2018). Other work explores the way food allergies are socially constructed via public discourses and the media (see Harrington et al. 2013; Abo, Slater, and Jain 2017).

Qualitative research on the everyday, lived experiences of those with food allergies has also increased. However, studies of allergic experience have disproportionately focused upon (1) key populations: children, teenagers, and parents (see Stjerna 2015; Otarnyk and Elliot 2016; Johnson and Woodgate 2017) and
(2) key spaces: schools and restaurants (see Kwon, Lee, and Wen 2020; Fenton, Elliott, and Clarke 2013). This focus is understandable: the burden of allergic disease in children is growing, heightened responsibilities for allergy management are borne by parents and teenagers, and allergy management often becomes more difficult within public versus private spaces. However, adult-onset allergies are increasingly common (Warren et al. 2018), and a focus upon particular spaces or phases of the life-course forecloses the potential for understanding the dynamicism of allergic experience.

Fenton, Elliott, and Clarke's (2013) study of the experiences of children with food allergies in schools is a valuable starting point from which this research builds. The authors offer a sense of the dynamicism of allergic experience as the school is framed as an "interrupted" space where changing characteristics such as a new teacher alter children's experiences. The scholars highlight the micro-level relations that come to matter to allergic experience, such as children's social relations to other bodies, like teachers. However, they also dichotomise the "interrupted," dynamic space of the school with the regulated, static space of the home, which possibly oversimplifies allergic experiences. Furthermore, limited existing research examines the interactions between the everyday, lived experiences of those with food allergies at the micro-level and the macro-level social, political, and economic factors that 
shape understandings and experiences of food allergies within society. Through a novel focus on bodily experiences in and through space, my research aims to bridge this gap and explore how allergic experience is mediated through relations both at the micro- and macro-level. A focus upon the allergic body as it passes through and encounters different spaces and circumstances exposes the dynamicism of allergic experience.

\section{Theorising the Body}

Over the past three decades, the body has become an important site of social science inquiry. Scholars have asked questions of what the body is (Longhurst 1997), what the body does (Deleuze 1992), what else becomes important for/to the body (Butler 2014), and what brings the body into being (Latour 2004). Gillian Rose's (1993) seminal critique of geography's treatment of the body as universal has fuelled a proliferation of efforts to delineate the specificities of the " $X$ " body (see Probyn 2016; Colls 2007). However, the question of the allergic body has yet to be taken up. To work towards a theorisation of the allergic body as recalibratory, I draw upon the interdisciplinary contributions of feminist theories of embodiment, actor-network theory, affect theory, and work around the biopolitics of health.

\section{Embodiment and Bodily Relations}

The feminist concept of embodiment is foundational to understanding everyday allergic experience. Emerging from Merleau-Ponty's (1962) phenomenology, the concept emphasizes that what it means to have a body is to experience life corporeally-through the body (Grosz 1994). For those with allergies, this bodily experience of life is more pronounced as individuals may experience a heightened awareness of both their bodies and their body's relations. This idea of the body's relations refers to other bodies or materials that may be typically considered "external" to the body yet can come to shape an individual's bodily experience. Bodily relations include and go beyond "social" relations. For instance, in Fenton, Elliott, and Clarke's (2013) study, the presence of a new teacher who is unaware of a child's allergy impacts a child's feeling of security within the school-this other body becomes important to a child's allergic experience on account of the body's relations.

The allergic body's relationship with that which may be considered external to it is therefore important. Early feminist literature has critiqued understandings of the body as a bounded, discrete unit. For instance, Longhurst (2001) describes how the body interacts openly with space and material external to it. Considering the body and its inter-relations with space becomes valuable when considering the potential for the allergic body to react through an exposure to allergens (NHS 2019). However, my research demonstrates that the allergic body's relations encompass far more than its allergens alone; rather, various social and material arrangements can be considered integral to what the body is (see Butler 2014). Where we consider embodiment, the questions of which bodily relations come to matter to allergic experience and how they shape it become important (Evans, Colls, and Hörschelmann 2011).

I draw on the work of Nikolas Rose and Paul Rabinow to understand why both (1) a heightened bodily awareness and (2) the body's relations become particularly important to the experience of allergic individuals. Like all individuals, those with food allergies have a responsibility to manage their own health via their bodies (Rose 2001). However, their chronic condition provides an expectation to manage their allergies by avoiding exposure to allergens (NHS 2019a). A level of bodily awareness of both the body and its relations becomes important to the allergic body as an allergy management practice.

Key normative assumptions as to how individuals "should" manage allergies stem from biomedicine. The UK's NHS advises all those with life-threatening allergies to carry prescribed AAls at all times (NHS 2019) in proximity to the body. However, as this research demonstrates, not all individuals with allergies perform this "responsibility" when managing their allergies. Through personal experience, individuals develop their own normative assumptions regarding how their allergy should be managed and may come to feel like the "expert" at managing their own 
health and body. The concept of "somatic expertise" can be extended to reflect this idea. Whilst Rose (2007) uses the concept to refer to qualified individuals (e.g., geneticists, therapists, allergists) with specialist knowledge, the term is also useful for reflecting the sense of bodily expertise an individual develops via their personal experience of managing a condition.

However, responsibilities for health management extend beyond the individual (Rose 2007). Members of an individual's social network or particular organisations can assume responsibility for the health of others and similarly have normative assumptions around how conditions should be managed. These people and groups too may gain "somatic expertise" of allergy management. In this research, I find that others' normative assumptions surrounding allergy management can impact an individual's allergic experience. Rabinow (1996) proposes the term biosociality to refer to a collective that is brought together around a shared biomedical knowledge or condition. Biosocialities that are brought together around the allergic body may include individuals with allergies, parents/caretakers, friends, teachers, physicians, patient organisations such as the Anaphylaxis Campaign, and their associated support groups. This concept is useful to exemplify the types of social bodily relations that have the potential to influence the allergic body and shape individuals' allergic experience.

\section{The Body as Affected}

The concept of affect (see Anderson 2016) is useful to account for why the body's relations can be considered integral to what the (allergic) body is. The verb "affect" refers to something that has an effect on or makes a difference to something (Oxford Dictionaries 2021). It is useful to recognise the potential for the body's relations to do something, to affect the body as well as the body's capacity to be affected by them (Latour 2004). I use the term "affective relation" to recognise this potential for the allergic body's relations to do something to it. Should allergic bodies be viewed through the lens of binary states (healthy versus in reaction to an allergen) without consideration of affect, we would be unable to account for the multiple ways in which the "healthy" allergic body is affected by its relations on an everyday basis as it passes through and encounters different spaces and circumstances.

As aforementioned, the allergic body's relations encompass social relations not only with other bodies but also with materials. For those with food allergies, the body's affective relation to the biomedically prescribed AAI is particularly important, yet individuals affectively relate to the AAl in multiple ways. The AAI performs a mediatory role in the relationship between the allergic body and space, shaping an individual's awareness of the body and its relations. Considering the work of Bruno Latour, Michael Serres, and Judith Butler is valuable for understanding the paradoxical ways that the AAl comes to mediate this affective relationship and the different ways in which the AAl may come to matter to the allergic body.

Latour (2005, 207-8) equips us with the language to consider the body's capacity for affect as conditional. He argues that the body trains to be affected via mediatory materials. Latour draws upon the example of odour kits containing differing fragrances to explain this idea. Specialists in the perfume industry are trained to become sensitive to these differences. However, it is the odour kit that acts as a mediatory tool through which the body gains the capacity to differentiate fragrances. The odour kit facilitates the body's capacity to be affected by these different smells and therefore distinguish between them. Could the AAl tool behave like the odour kit, heightening the allergic body's awareness and capacity to be affected?

Similarly, Serres' (1982) concept of the quasiobject highlights the mediatory role of an object that bring both the subject and the collective into being through its possession by an individual. The quasi-object plays a mediatory role as it exposes the individual who possesses it to other individuals, therefore increasing the individuals' capacity to be affected by others.

Throughout my analysis, we find that it is the AAl that brings the allergic body into being, increasing its capacity to be affected by others' normative judgements about how to manage one's allergy. For those living with allergies, it is therefore not simply their biological identity 
that results in this sense of responsibility (Rose 2001), but the biomedical prescription of the AAl as a tool through which to manage food allergies: the AAl has the capacity to bring biosocialities of allergic and non-allergic bodies together around the health management of individuals with food allergies (Rabinow 1996).

Finally, Judith Butler's (2016) concept of corporeal vulnerability is useful to consider the AAl alternatively as an infrastructural support for the allergic body. For Butler, the body is inherently vulnerable-its supports are integral to what the body is. However, this corporeal vulnerability only becomes visible once its infrastructural relations are removed. This research finds that for some individuals, the AAI becomes a supportive tool for the allergic body. Its supportive, mediatory role is exposed when the tool is forgotten, resulting in a heightened awareness of the body's relations.

\section{Towards the Body as Recalibratory}

As I work towards a theorisation of the recalibratory body, it is useful to turn to its etymology. Recalibration stems from the verb "calibrate," which refers to the gauging of an instrument (for instance) against a standard (Oxford Dictionaries 2020b). For those with allergies, this standard is the normative biomedical expectation to always carry the AAl. As my research demonstrates, all those with allergies affectively relate to the AAI, yet they do so in multiple ways. Allergic bodies can be said to recalibrate from this biomedically prescribed relation to the AAI.

Actor-network theory becomes useful to account for a second key research finding: how those living with food allergies affectively relate to the AAl is dynamic and changes over time. By considering the allergic body as positioned within Latour's (2005) assemblage of the social-which positions society as constructed by the coming together of many individual parts-we gain an appreciation of the dynamicism of the body's relations as the allergic body may be affected by multiple, reassembling relations that are constantly in flux. I consider how the body's relations may be shaped by other material and social arrangements in this broader assemblage, which is the key insight into the dynamicism of the body's affective relations and becomes instrumental to working towards a theorisation of the body as recalibratory.

My analysis proceeds as a series of vignettes that intertwine autoethnographic, cognitive mapping, and interview data to demonstrate what comes to matter to myself and others' allergic experience. More specifically, I consider what contributes to individuals' affective relations to the $\mathrm{AAl}$ and their normative assumptions around allergy management.

\section{The AAI is Integral to the Allergic Recalibratory Body}

For the majority of allergic individuals in this study, the AAl emerged as a valuable insurance to be relied upon should any allergen exposure occur. However, the AAl matters beyond this moment of allergen exposure for all of my participants, becoming important more broadly to their bodily experience within space. For instance, university student Phoebe's reliance on the AAl came to the fore during her cognitive mapping activity: she drew the space of her high school prom as a time in which she was particularly aware of her food allergy (see figure 1). Phoebe has been working towards managing her allergy with greater confidence over the past couple of years, and she explained that this time was particularly difficult as she had forgotten her AAl:

The food was covered in like a sauce and that scared me cause I didn't know like what it was *sniffs* I didn't have that safety net there... it was a bit dark so you couldn't really see what you were eating...there were two boys on my table and I was like they must think I'm an absolute psychopath cause they'd just gave me a food and l'd like just cry. *laughs*

What is striking is the level of detail and specificity that Phoebe provides of her allergic experience. In the absence of "that safety net" of the AAI in proximity to her body, Phoebe is increasingly sensitised to and aware of the material and social arrangements in this space. It is therefore only in its absence that how the AAl matters to the allergic body comes to light: in mediating the body's affective relationship with its relations. As opposed to heightening the body's capacity to be affected by its relations as in Latour's (2004) account, the 


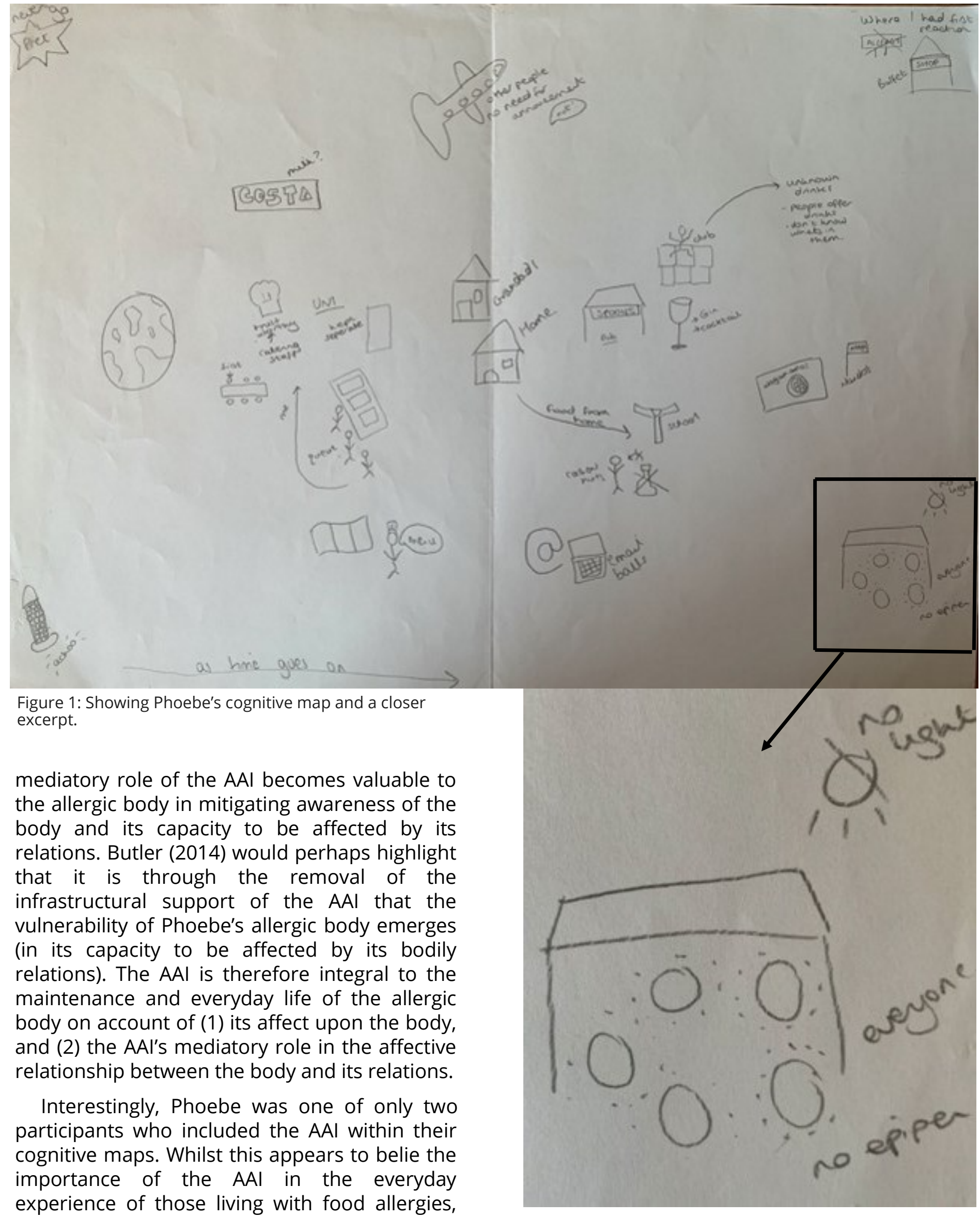


accounts for these absences. For instance, whilst AAls remain absent from my own cognitive map (figure 2), an analysis of autoethnographic data reveals their mediatory role and large importance in my preparation for a trip to Nepal.

In an entry written towards the end of my trip, I reflect upon an experience of eating out at a restaurant:

I only realised after I'd gotten back from dinner that night, but l'd taken my EpiPen out of my bag in all the commotion. I'd actually gone for something really different to eat as well, a mutton paneer curry. I would have never ordered on my own but someone else had suggested that we split it. I can remember saying “It doesn't look like it has nuts in" and taking it slow, but I wonder if I'd have acted different, or even not ordered something new should I have realised at the time.

Autoethnography Entry - 17/09/19

Here, I appear to recognise the affect of the AAI upon my allergic body and its mediatory role as I consider the potential that my experience and the decisions I made may have been different had I realised its absence. The AAl was

Figure 2: Showing my cognitive map and a closer excerpt. particularly important to my allergic experience when travelling abroad, and making sure to take plenty of AAls was a typical allergy management practice for me. This was of similar importance to other participants like Michelle, who mentioned that she employs this strategy to manage her shellfish allergy when travelling: "I must admit I take double EpiPen's, my GP gives me a second prescription so in the hotel room I can keep a backup, in case anything goes missing." The mediatory role of the AAI therefore becomes valuable in enabling those living with food allergies to both access and feel comfortable within particular spaces.

As the importance of the AAl to the allergic body becomes clear, we begin to gain a sense of how and why issues like AAl shortages and AAl involvement in the circumstances around allergy deaths may come to matter to the

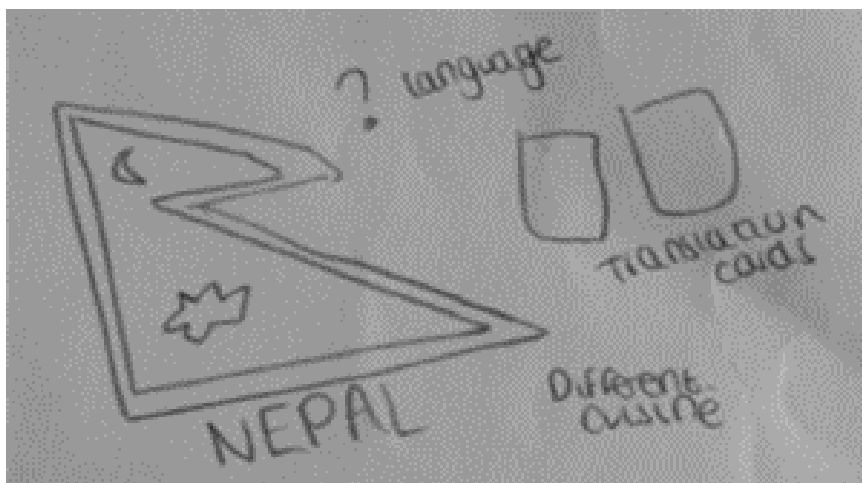

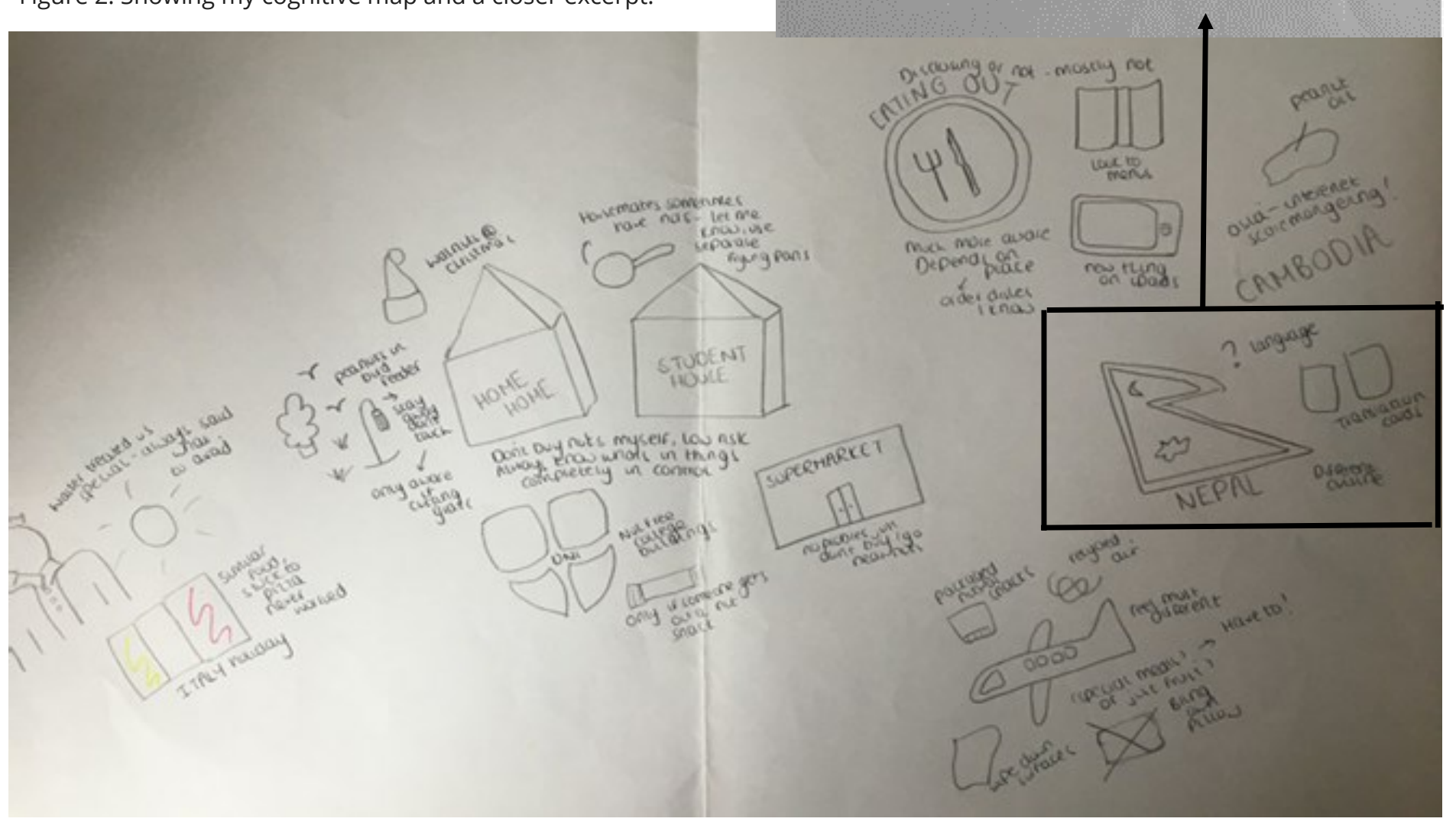


allergic experience of those with allergies. However, the centrality of the AAI to the allergic body can be complicated through my research finding that individuals relate differently to it. For instance, both Jake and Dave completely rejected the need to carry the AAl to manage their food allergies.

University student Jake does not feel he needs an AAl to manage his peanut allergy because his past allergic reactions have never required one. He explains, "I've always tried to sort of distance myself from the EpiPen... I don't like having it around as a sort of reminder which I don't feel like I need." In his choice not to carry the AAl, the way in which Jake relates to the tool differs greatly from the way that the AAl comes to matter for Phoebe, Michelle, and myself. Nonetheless, the AAl still does something to Jake, affecting his allergic body. Unlike the quasi-object (Serres 1982), the AAI does not require possessing to bring the allergic body into being. Rather, it is the bioindustrial tool of the AAI and its prescription to individuals to manage their allergy that becomes integral to what the allergic body is.

Similarly, Dave, who has been managing his peanut allergy for over forty years, is confident that he does not need an AAl. However, through close analysis I found that it is his recognition of the mediatory role of the $A A I$ and its effect on the allergic body that contributes to the way he relates to the tool: "What I've heard other people say [is], they're not as careful cause they know they've got the pen." For Dave, this mediatory role of the AAI undermines an individual's ability to manage their allergy. He alludes to the potential that carrying an AAI reduces an allergic individual's awareness of and capacity to be affected by their body and its relations (Latour 2004). In this way, the mediatory role of the AAI appears to make the allergic body vulnerable as opposed to providing infrastructural support (Butler 2014). This finding complicates Butler's (2016) theorisation of corporeal vulnerability, highlighting that there may be multiple ways in which the body can be made vulnerable. What is also striking here is the indication that gender may play an important role in the different ways in which individuals affectively relate to the AAI. How bodily experience is connected to gender, sexuality, and other aspects of identity is well-established within the literature by scholars such as Ahmed (2006). However, further research with a more representative sample is needed to consider whether a denial of the body's vulnerability or sense of control of the body without the aid of medical devices may be seen as a gendered form of embodiment.

Despite both Dave and Jake's rejection of the need to carry an AAl, we see that it still affects their allergic bodies. On account of its biomedical prescription, my research found that all of my participants living with food allergies affectively relate to the AAI. Following Butler (2014), the allergic body is therefore untheorisable outside of its affective relation to the AAI. However, I also found that there are multiple ways in which individuals affectively relate to the AAI. The AAI can be said to, in fact, bring multiple allergic bodies into being (Mol 2002). In rejecting the need to carry an AAI, both Jake and Dave reject the normativity of this allergy management practice. Their allergic bodies can be said to have recalibrated away from this normative biomedical expectation to always carry the AAI. To return to the etymology of the recalibratory body: as a transitive verb, for something to recalibrate requires an object (Oxford Dictionaries 2020a). For allergic bodies, it is the AAl that becomes important to the body's recalibration and allergic individuals' experience of particular spaces.

\section{The Allergic Recalibratory Body as Affected}

To complicate our understanding of the allergic body, Dave's account of his allergic experience can be scrutinised further to more closely consider the role of affect. I found that it is Dave's implicit judgement of the ways that others with food allergies relate to the AAl that contributes to his affective relation to the tool. $\mathrm{He}$ is critical of the way that many of the other participants interviewed in this study relate to the $\mathrm{AAl}$ and their normative assumptions around allergy management. Dave's allergic body therefore appears to have been affected by others' differing normative assumptions around allergy management. Considering the role of affect enables us to appreciate how 
others' normative assumptions around allergic management may come to matter to individuals with the potential to affect the allergic body. It is clear that what matters to the everyday experience of allergic individuals extends far beyond allergen exposure, as may be presumed through a binary lens.

My own experiences offer insight into this potential for allergic bodies to be affected by and recalibrate in response to other allergic bodies due to differing normative assumptions around allergy management. During my flight to Nepal, I recount::

When I got up from my seat to go to the toilet, a member of the cabin crew offered me the cardboard cup that was on the sidenaturally, it was a cup of peanuts the staff had been snacking on. He put it right under my face and I felt myself lean away. I found myself eyeing the hands of staff that was making my tea that I'd just asked for, wondering whether she'd had some and had washed her hands since. I was annoyed at myself for not actually knowing whether the trace of peanuts would actually affect me. I took an allergy tablet just in case-this isn't actually something I'd ever done before, more as a preventative measure than anything.

Autoethnography Entry - 18/08/19

Close analysis reveals that my adoption of this novel behaviour emerged closely following my interview with Amanda, who spoke of her allergy management practices and strategy to "load...[her] system" with allergy tablets in preparation for a flight. Hearing of the normativity of such practices for Amanda appears to have affected my allergic body, altering what I did to manage my allergy on this occasion. My allergic body can be said to have recalibrated in response. At the time, I was unaware of how my interview with Amanda had affected my allergic body, which highlights the possibility for the body's recalibration to operate below the level of consciousness, as recognised in affect (Anderson 2016). It was only through the complementary analysis of autoethnographic and interview data that this bodily recalibration came to light. The concept of the recalibratory body enables us to recognise this potential for the allergic body to be affected by and recalibrate in response to an encounter with others' normative assumptions around allergy management. This example shows that not only do multiple kinds of allergic bodies exist on account of their differing affective relations to the AAI (Mol 2002), but also they have the potential to influence each other via affect.

However, I also found that this potential for allergic bodies to be affected and recalibrate is not limited to other allergic bodies. For instance, Jake reveals that, on occasion, he has been unable to distance himself completely from the AAI. On a recent trip to Singapore, his girlfriend's parents wanted him to bring it along: "I didn't want to bring this EpiPen, but I was being forced to...it was stressful not because I was worried about it but because of others, there was an external influence." In adopting responsibility for Jake's allergy management (Rose 2007) with differing normative assumptions, his girlfriend's parents had the potential to affect his allergic body.

It is therefore the biomedical prescription of the AAl that exposes Jake's allergic body to the normative judgements of his girlfriend's parents. A second, alternative mediatory role of the AAl emerges within these research findings: the AAl exposes allergic bodies, increasing their capacity to be affected by others' differing normative assumptions around allergy management. On account of its biomedical prescription, the AAI brings not only the allergic body into being but also a biosociality of individuals with the capacity to affect it, both resulting in its recalibration (Serres 1982; Rabinow 1986). The AAI plays a paradoxical, mediatory role in shaping the relationship between the allergic body and its relations: both mitigating and increasing its capacity to be affected. When we talk of allergic bodies, we therefore must recognise that we are also talking of the other allergic and non-allergic bodies that come to matter to an individual's allergic experience. These are examples of the bodily relations that may come to matter to the everyday bodily experience of those with allergies in their affect upon the allergic body.

Yet, as we know, Jake's normative assumptions around allergy management and 
his affective relation to the AAl does not alter as a result of the views of his girlfriend's parents. A final turn to etymology is useful to remind us that it is the concept of the recalibratory body as opposed to the calibratory body that is advanced through this research. To recalibrate is to "calibrate again or differently" (Oxford Dictionaries 2020a). The concept of the body as recalibratory therefore recognises the ongoing potentia/for the body to recalibrate as the body is affected by its relations. The exposure of the allergic body to others' differing normative assumptions about allergic management does not presume its recalibration will lead to a change in its affective relation to the AAI.

What contributes, then, to the emergence of bodily recalibration? My fieldnotes following my interview with Amanda provides some indication of this. Amanda's allergic experience was unusual amongst my participants; with multiple, late-onset food allergies, her proactive approach to allergy management and familiarity with using the AAl surprised me. She reflects that "The hardest thing to do in the world is to stab yourself. Everything in your body says no, don't do that. So, you do it, but it lasts twenty minutes and [the paramedics] take 20 minutes to arrive." This specific insight into how long the adrenalin released from AAls lasts once administered was shocking and new information for me. In her display of such knowledge, Amanda becomes an individual who I view to have experience and authority in managing her allergy. It is perhaps my own assumptions of her somatic expertise (Rose 2007) that may have contributed to my body's recalibration on this occasion: my allergic body is affected in hearing her speak so confidently about her allergy management. This meant that in my moment of surprise and uncertainty when encountering peanuts on the plane to Nepal, I followed her approach and adopted her normative allergy management strategy. Of course, other aspects of our positionalities beyond our allergic identities, such as our age difference (Moss 2005), may have contributed to why my allergic body was affected by Amanda's normative assumptions around allergy management, resulting in its recalibration. Nonetheless, this demonstrates that the specific dynamics of bodily recalibration depend upon the (allergic) body in question and the particular relations that come to affect it.

\section{Complicating the Allergic Body as Recalibratory}

Throughout this analysis, a complex theorisation of the allergic body and its potential for recalibration has emerged. Through Michelle's, Jake's, and my autoethnographic account, we gain a sense of the dynamicism of the allergic recalibratory body in its potential to be affected by others' normative judgements around allergic management. A second key finding of this research has emerged: how individuals affectively relate to the AAl is not fixed but dynamic. However, this potential for bodily recalibration can extend beyond an individual's immediate experience and social relations. This final section of analysis begins to explore the broader expanse of bodily relations at the macro-level that may contribute to the allergic body's recalibration.

Like many participants, carrying the AAI was something that always used to reassure university student Zoe: "In my head then I think, I've got the medication and that will work." However, hearing of the death of Natasha Ednan-Lapernouse has meant the way Zoe affectively relates to the AAI has altered: "...that was what was so scary about the girl on the plane because she'd had two EpiPen's and they didn't work." Zoe's concerns are remarkably similar to Dave's whose rejection of the need to rely upon the AAl is also informed by its potential to fail. And yet in Zoe's interview, we are able to identify exactly where these concerns stem from: her allergic body was exposed to the potential to be affected through hearing an interview with Natasha's father on the radio. This highlights the potential that circumstances beyond one's immediate experience and bodily relations may contribute to the allergic body's recalibration.

As such a high-profile case, EdnanLapernouse's tragic death has had a large impact upon many within the allergic community. Kate Latchford of the Anaphylaxis Campaign spoke of the particular spaces that those with food allergies often fear or avoid: "Planes, especially after what happened to 
Natasha, people are particularly scared about how allergies are treated on planes." Latchford recognises the potential for factors beyond an allergic individuals' immediate experience to affect their everyday experiences. Furthermore, a key aspect of Latchford's work as Outreach Coordinator involves the overseeing of local support groups, which are "safe, neutral spaces" for those to reach out for support and share personal experiences. Of key priority is the dissemination of information, such as new research, updates on the supply of AAls, and inquest outcomes regarding allergy fatalities. Not only does the Anaphylaxis Campaign recognise the wider expanse of bodily relations that come to matter to allergic experience, but also the organization becomes part of them. The NGO acts to mediate how such news reaches and (potentially) affects allergic individuals, thereby playing a role in the allergic body's recalibration. The NGO is part of the allergic body's wider field of re-assembling affective relations and biosociality that may contribute to its recalibration (Latour 2005; Rabinow 1996).

Latchford's interview highlights the further macro-issue of AAl production that becomes important to the allergic recalibratory body. In this study, AAl supply issues came to matter to the everyday allergic experience of many research participants, including myself. Within my autoethnographic data, this affected my allergic body during my preparation to travel to Nepal:

I did get a prescription for more [AAls] a whole four weeks ago (which is really responsible for me!) but I haven't been able to get a hold of any. I just kept getting told to try somewhere else. The clocks definitely ticking, but the fact they've got such supply issues is frankly ridiculous.

\section{Autoethnography Entry - 10/08/19}

As I discussed, obtaining AAls when travelling abroad is a normative allergy management strategy that I had used repeatedly in the past. However, the ease with which I can enact this management strategy falls in light of AAI shortages and the UK's prescription validation process (Kent 2020). This policy change results in a bodily recalibration of my sense that this is a normative allergy management practice: the shortages disrupt my long-held practice of obtaining extra AAls when abroad; therefore, it can no longer be a norm within my allergy management. Contextualised within these supply issues, it is interesting to consider that Michelle's perception of obtaining extra AAls as a non-normative allergy management strategy (and her confessional tone) can be accounted for as she perhaps has greater awareness of the policy change or encountered this new policy before I did.

Whilst experiencing these difficulties, I began to question the adequacy of my own allergy management, throwing doubt upon my estimations of my own somatic expertise (Rose 2007):

I did manage to get a hold of two Jext pens in the end. l'd never heard of these ones and so when I collected them, the pharmacist explained how to use them. I remember feeling really ashamed when I realised I had no idea of the differences between how he said you use the Jext pen than the EpipenI've been so used to having it there as a safety net and yet if anything actually did happen, I wouldn't even know how to use it properly. I think this realisation, along with speaking to allergic individuals in my interviews, has made me sort of look back at myself, thinking I'm not actually managing it well enough at all, I'm being too lax about it.

\section{Autoethnography Entry - 17/08/19}

Through this passage, it becomes clear that multiple bodily relations come to matter to my allergic experience and combine to undermine my sense of somatic expertise. Not only does the UK's policy implementation around prescriptions come to affect my allergic body, but also the research process, through exposure to others' differing normative assumptions around allergy management, prompt its recalibration. The recalibratory body allows us to appreciate the implications of macro-level factors such as key policy changes and incidences of allergy fatalities on the everyday experiences of those living with allergies. Its further value emerges in its insight into the broader field of affective relations and biosocialities that have the potential to interact and affect the allergic body, including a social 
encounter, the work of organisations such as the Anaphylaxis Campaign, and the political economy of AAI production.

\section{Conclusion}

Through an investigation of the everyday experiences of those living with food allergies, this research has worked towards a theorisation of the body as recalibratory. Following Butler's (2014) work, this research finds that the body's relations are integral to how individuals with food allergies experience their body, yet these relations come to matter specifically on account of their capacity to affect it. The body as recalibratory foregrounds the dynamicism of the body and the way that it is constituted in relation to shifting material and social arrangements. I found that dynamic bodily relations at both the micro- and macro-level have the potential to affect the allergic body and contribute to its recalibration.

An understanding of the body as recalibratory also foregrounds the vulnerability of the allergic body in its capacity to be affected by its relations. It offers a more complex, dynamic appreciation of corporeal vulnerability (Butler 2016) on account of the multiple ways in which individuals relate to the AAl and its mediatory role: I found that not all allergic bodies are made vulnerable in the same way. In this research, it becomes clear that multiple allergic bodies exist, each with the potential to affect (and be affected by) each other. For allergic bodies, the pluralisation of responsibilities for health management and differing normative judgements around allergy management are important to recalibration.

However, the value of the recalibratory body concept extends beyond its ability to account for the experiences of allergic individuals. The concept does not presuppose any specificities of the body. In fact, it challenges the very idea that the specificities of any one body can be theorised, highlighting the limits of recent feminist endeavours to theorise the specificities of the " $X$ " body (see Probyn 2016). We cannot theorise any singular " $X$ " body in light of the multiple other " $X$ " bodies in existence that come to affect what this " $X$ " body is. Instead, the recalibratory body's value arises in its invitation to question what specifically contributes to the way other bodies recalibrate and why. It allows us to ask of any and all bodies what materials may become important to their recalibration, performing a mediatory role.

In beginning to think about bodily recalibration, we are confronted with fruitful possibilities for further research. Posthumanists, for instance, may further interrogate the human-non-human, socialmaterial relations that come to matter to the body's recalibration or question the extent to which the recalibratory body has arisen through the advancement of technologies like the AAl. Questions arise as to whether there may be gendered, racial, age, etc. dimensions to the recalibratory body. For instance, it is perhaps telling that the two participants who rejected any need for the AAI were both men, and little sense of doubt at the normativeness of their allergy management was traced amongst an analysis of their interviews (unlike in both Michelle's and my own experiences). Feminists may prioritise a consideration of the intersecting aspects of identity (Crenshaw 1991) that may come to matter to the body's calibration. The experiences of a limited cohort of allergic individuals are highlighted in this study: multiple allergic bodies exist in excess of those engaged with in this research, not least because of its geographic limits within the UK. The mediatory role of the AAl may differ in other settings where access to medications is constrained by a lack of financial resources, and socioeconomic status may play an important role in the allergic body's recalibration. Further research in other contexts is therefore imperative to move beyond the western-centrism that characterises existing literature on food allergies.

The concept of the (allergic) body as recalibratory also offers a new way of thinking through the methodological implications of the research encounter upon both participants and the researcher (England 2015). Whilst autoethnography proved instrumental to the theorisation of the body as recalibratory, the concept also enabled me to appreciate that engaging in this immersive method impacted my allergic body. This raises important ethical considerations surrounding autoethnography's implementation. Nevertheless, as this research makes clear, the ongoing potential for a large 
expanse of bodily relations to affect my allergic body and contribute to its recalibration at both the micro- and macro-level means that my allergic experience can and will continue to change throughout the course of my life. 


\section{Acknowledgements}

A huge thank you to my supervisor Dr Elizabeth Johnson for your encouragement to adapt my dissertation for publication. Thank you once again for all those who gave up their time to share with me your experiences of living with food allergies and to the team at the Anaphylaxis Campaign for allowing me to gain insight into its valuable work to support those with severe allergies. This was an enjoyable first peer-review process; thank you to Dr Martha Radice and all at JUE. Finally, thank you to my family and your unwavering support of my every endeavour. 


\section{References}

AAFA. 2015. "Allergy Overview." Asthma and Allergy Foundation of America. Accessed August 28, 2020. https://www.aafa.org/ allergies.aspx.

Abo, Melissa M., Michael D. Slater, and Parul Jain. 2017. “Using Health Conditions for Laughs and Health Policy Support: The Case of Food Allergies." Health Communication 32 (7): 803-11. https:// doi.org/10.1080/10410236.2016.1172292.

Ahmed, Sarah. 2006. Queer Phenomenology: Orientations, Objects, Others. Durham: Duke University Press.

Anaphylaxis Campaign. 2018. "Statement regarding inquest into Natasha Ednan-Laperouse." Anaphylaxis Campaign. Accessed August 28, 2020. https://www.anaphylaxis.org.uk/2018/09/25/ statement-regarding-inquest-into-of-natasha-Ednan-Laperouse/.

Anderson, Ben. 2016. "Researching Affect and Emotion." In Key Methods in Geography, 3rd ed., edited by N. Clifford, M. Cope, T. Gillespie, and S. French, 182-198. London: SAGE Publications Ltd.

Butler, Judith. 2014. "Rethinking vulnerability and resistance." Madrid, June 2014. Accessed September 10, 2021. http://bibacc.org/wpcontent/uploads/2016/07/Rethinking-Vulnerability-andResistance-Judith-Butler.pdf.

Butler, Judith. 2016. "Re-Thinking Vulnerability and Resistance." In Vulnerability in Resistance, edited by J. Butler, Z. Gambetti, and L. Sabsay, 12-27. Durham, NC: Duke University Press.

Butz, David. 2010. "Autoethnography as Sensibility." In The SAGE Handbook of Qualitative Geography, edited by D. DeLyser, 138155. London: SAGE Publications Ltd.

Butz, David, and Kathryn Besio. 2009. "Autoethnography." Geography Compass 3 (5): 1660-1674. https://doi-org.ez.Ishtm.ac.uk/10.1111/ j.1749-8198.2009.00279.x.

Colls, Rachel. 2007. "Materialising bodily matter: intra-action and the embodiment of 'fat."' Geoforum 38: 353-365. https://doiorg.ez.Ishtm.ac.uk/10.1016/j.geoforum.2006.09.004.

Crenshaw, Kimberle. 1991. "Mapping the Margins: Intersectionality, Identity Politics and Violence Against Women of Colour." Stanford Law Review43 (6): 1241-1299. 
England, Kim. 2015. "Producing Feminist Geographies: Theory, Methodologies and Research Strategies." In Approaches to Human Geography, edited by S. Aitken and G. Valentine, 286-298. London: SAGE Publications Ltd.

Evans, Bethan, Rachel Colls, and Kathrin Hörschelmann. 2011. “'Change4Life for your kids': embodied collectives and public health pedagogy." Sport, Education and Society 16 (3): 323-341. https://doi.org/10.1080/13573322.2011.565964.

Feng, Charles, and Jea-Hyoun Kim. 2019. “Beyond Avoidance: The Psychosocial Impact of Food Allergies." Clinical Reviews in Allergy \& Immunology 57 (1): 74-82. https://doi.org/10.1007/s12016-0188708-x.

Fenton, Nancy E., Susan J. Elliott, and Ann Clarke. 2013. “Tag, you're different: the interrupted spaces of children at risk of anaphylaxis." Children's Geographies 11 (3): 281-297. https:// doi.org/10.1080/14733285.2013.812273.

FSA. 2019. "Food allergen labelling changes become law." Food Standards Agency, September 5, 2019. Accessed September 10, 2021. https://www.food.gov.uk/news-alerts/news/food-allergenlabelling-changes-become-law.

Gieseking, Jack J. 2013. "Where we go from here: The Mental Sketch Mapping Method and it's Analytic Components." Qualitative Inquiry 19 (9): 712-724. https://doiorg.ez.Ishtm.ac.uk/10.1177/1077800413500926.

Grosz, Elizabeth. 1994. Volatile Bodies: Towards a Corporeal Feminism. St Leonards, NSW: Allen and Unwin.

Hayes-Conroy, Allison. 2010. “Feeling Slow Food: Visceral Fieldwork and Empathetic Research Relations in the Alternative Food Movement." Geoforum 41: 734-742. https://doi.org/10.1016/ j.geoforum.2010.04.005.

Harrington, Daniel W., Susan J. Elliot, Ann E. Clarke, Moshe BenShoshan, and Samuel Godfrey. 2012. "Exploring the Determinants of the Perceived Risk of Food Allergies in Canada." Human and Ecological Risk Assessment: An International Journal18 (6): 133858. https://doi.org/10.1080/10807039.2012.722857.

Johnson, Sara F., and Roberta L. Woodgate. 2017. “Qualitative Research in Teen Experiences Living with Food-Induced Anaphylaxis: A Meta-Aggregation." Journal of Advanced Nursing 73 (11): 2534-46. https://doi.org/10.1111/jan.13325. 
Kent, Chloe. 2020. "EpiPen shortages: prospects brighten for UK supply." Medical Device Network. Accessed August 28, 2020. https://www.medicaldevice-network.com/features/epipen-supply -chain-2020/.

Kwon, Junehee, Yee Ming Lee, and Han Wen. 2020. “Knowledge, Attitudes, and Behaviors about Dining out with Food Allergies: A Cross-Sectional Survey of Restaurant Customers in the United States." Food Contro/107: 106776. https://doi.org/10.1016/ j.foodcont.2019.106776.

Latour, Bruno. 2004. "How to Talk about the Body? The Normative Dimension of Science Studies." Body \& Society 10 (2-3): 205-229. https://doi-org./10.1177/1357034X04042943.

Latour, Bruno. 2005. Reassembling the Social: An Introduction to Actor Network Theory. New York, NY: Oxford University Press.

Loh, Wenyin, and Mimi K. L. Tang. 2018. "The Epidemiology of Food Allergy in the Global Context." International Journal of Environmental and Public Health Research 15 (9): 2043. https:// doi.org/10.3390/ijerph15092043.

Longhurst, Robyn, Elsie Ho, and Lynda Johnston. 2008. "Using 'the Body' as an 'Instrument of Research': Kimch'i and Pavlova." Area 40 (2): 208-127. https://doi.org/10.1111/j.14754762.2008.00805.x.

Longhurst, Robyn. 2001. Bodies Exploring Fluid Boundaries. London, New York: Routledge.

Longhurst, Robyn. 1997. "(Dis)Embodied Geographies." Progress in Human Geography 21 (4): 486-501. https:// doi.org/10.1191/030913297668704177.

Merleau-Ponty, Maurice. 1962. The phenomenology of perception. Translated by C. Smith. London: Routledge.

Medicines and Healthcare products Regulatory Agency. 2019. "Adrenaline Auto-Injectors: Recent action taken to support safety." GOV.UK, October 18, 2019. Accessed September 216, 2021. https://www.gov.uk/drug-safety-update/adrenaline-autoinjectors-recent-action-taken-to-supportsafety\#: :text=Emerade\%20adrenaline\%20auto\%2Dinjectors\% 20are,the\%20injection\%20is\%20not\%20administered.

Mol, Annemarie. 2002. The body multiple: Ontology in medical practice. Durham, NC: Duke University Press. 
Moss, Pamela. 2005. "A Bodily Notion of Research: Power, Difference and Specificity." In A Companion to Feminist Geography, edited by L. Nelson and J. Seager, 41-59. Oxford: Blackwell Publishing.

NARF. 2019. "The Allergy Explosion." Natasha Allergy Research Foundation. Accessed August 28, 2020. https://www.narf.org.uk/ the-allergy-explosion.

NHS. 2019a. "Anaphylaxis - Prevention." NHS. Accessed August 28, 2020. https://www.nhs.uk/conditions/anaphylaxis/prevention/.

NHS. 2019b. "Food Allergy - Overview." NHS. Accessed August 28, 2020. https://www.nhs.uk/conditions/food-allergy/.

Olarnyk, Alexandra S., and Susan J. Elliot. 2016. "You're Totally on Your Own': Experiences of Food Allergy on a Canadian University Campus." Universal Journal of Public Health 4 (1): 31-37. https:// doi.org/10.13189/ujph.2016.040105.

Oxford Dictionaries. 2020a. "Meaning of Recalibrate by Lexico." Lexico. Accessed August 28, 2020. https://www.lexico.com/ definition/recalibrate.

Oxford Dictionaries. 2020b. "Meaning of Calibrate by Lexico." Lexico. Accessed August 28, 2020. https://www.lexico.com/definition/ calibrate.

Oxford Dictionaries. 2021. "Meaning of Affect by Lexico." Lexico. Accessed August 28, 2020. https://www.lexico.com/definition/ affect.

Probyn, Elspeth. 2016. “Following Oysters, Relating Taste." In Eating the Ocean, 49-75. NC: Duke University Press.

Rabinow, Paul. 1996. "Artificiality and Enlightenment: From Sociobiology to Biosociality." In Essays on the Anthropology of Reason, 91-111. Princeton, NJ: Princeton University Press.

Rose, Gillian. 1993. Feminism and geography: the limits of geographical knowledge. Polity Press: Cambridge.

Rose, Nikolas. 2001. "The Politics of Life Itself." Theory, Culture and Society 18 (6): 1-130.

Rose, Nikolas. 2007. The Politics of Life Itself: Biomedicine, Power and Subjectivity in the Twenty-First Century. Princeton, NJ:

Princeton University Press.

Serres, Michel. 1982. The Parasite. Translated by Lawrence R. Schehr. Baltimore, MD: Johns Hopkins University Press. 
Stjerna, Marie-Louise. 2015. “Food, Risk and Place: Agency and Negotiations of Young People with Food Allergy." Sociology of Health \& IIIness 37 (2): 284-97. https://doi.org/10.1111/14679566.12215.

Warren, Christopher, C. Stankey, J. Jiang, J. Blumenstock, B. Smith, and R. Gupta. 2018. "Prevalence, severity, and distribution of adult-onset food allergy." Annals of Allergy, Asthma \& Immunology121 (5): S14. https://doi.org/10.1016/ j.anai.2018.09.041.

Wearne, Steve. 2017. "Food Allergy and Intolerance Programme." Food Standards Agency. Accessed August 28, 2020. https:// www.food.gov.uk/sites/default/files/media/document/reportfood-allergy-intolerance-research-programme-review.pdf.

This work is licensed under a Creative Commons Attribution-NonCommercialNoDerivatives

4.0 International License. 